\title{
New Technologies for Treatment of Coronary Artery Disease
}

\author{
Ram B Singh ${ }^{1}$, Viliam Mojto*2, Jan Fedacko ${ }^{3}$, Ghizal Fatima ${ }^{4}$, Adrian Isaza ${ }^{5}$ and Dr Kumar Kartikey ${ }^{6}$ \\ ${ }^{1}$ Halberg Hospital and Research Institute, India \\ ${ }^{2} 3^{\text {rd }}$ Internal Clinic Faculty of Medicine Comenius University Bratislava, Slovakia, Europe \\ ${ }^{3}$ PJ Safaric University, Kosice, Slovakia, Europe \\ ${ }^{4}$ Era Medical College, Lucknow, India \\ ${ }^{5}$ Everglades University, Tampa, USA \\ ${ }^{6}$ Halberg Hospital and Research Institute, Moradabad, India
}

Received: 制 January 16, 2019; Published: 制 January 23, 2019

*Corresponding author: Viliam Mojto, $3^{\text {rd }}$ Internal Clinic Faculty of Medicine Comenius University Bratislava, Slovakia, Europe

\begin{abstract}
The existing treatment for acute and chronic coronary artery diseases (CAD) is medical, surgical or a combination of both depending on the extent, severity and clinical presentation of CAD. The collaboration between different science disciplines such as biotechnology and tissue engineering has led to the development of novel therapeutic strategies such as stem cells, nanotechnology, robotic surgery and other advancements (3-D printing and drugs). These therapeutic modalities indicate, a promising effects in managing CAD and associated complications. Research on stem cells focuses on studying the potential for cardiac regeneration, while nanotechnology research investigates nano-drug delivery and percutaneous coronary interventions including stent modifications and coatings. Many of these technologies are in practice but still need improved version because, despite their use, mortality and morbidity due to CAD and heart failure continue to be high.
\end{abstract}

Keywords: Nanotechnology; Stem Cells; Stents; Gene Therapy; Coronary Intervention

Abbreviations: CVDs: Cardiovascular Diseases; AMI: Acute Myocardial Infarction; PVN: Paraventricular Nucleus; RVLM: Rostral Ventrolateral Medulla; AP: Area Postrema; CHF: Chronic Heart Failure; LVEF: Left Ventricular Ejection Fraction

\section{Introduction}

Despite tremendous advances in therapy and prevention, cardiovascular diseases (CVDs), including acute myocardial infarction (AMI) and its complication heart failure, are the leading causes of death worldwide [1-3]. Therefore, translational research and basic science becomes necessary to discover the novel mechanisms responsible for cardiovascular repair during athero-thrombosis which results in to AMI [4-6]. The inflammatory tissue in the myocardium and the intensity of neuro-humoral dysfunction after AMI are important determinants of complications as well as subsequent healing process. The increase in leucocytes; neutrophils, macrophages and lymphocytes in the myocardium contribute to the clearance of dead cells from the myocardial tissues while activating reparative pathways necessary for myocardial remodeling [5,7]. The thinning of the wall occurs due to apoptosis of cardiomyocyte with triggering of ventricular dilation and subcellular remodeling, leading to left ventricular dysfunction
[7-9]. The underlying mechanisms appear to be increase in cortisol and vasopressin causing neuro-humoral dysfunction and oxidative stress, leading to inflammation and apoptosis [8-10].

Activation of angiotensin II signalling in different brain sites; the paraventricular nucleus (PVN), rostral ventrolateral medulla (RVLM), and area postrema (AP) may cause increased cardiac contractility with worsening of HF [8].The increase in angiotensin II signalling in the brain, enhances sympathetic nerve activity through actions on both central and peripheral sites during chronic HF. Stem cell therapy to target these brain areas may be an important technology to benefit patients with HF. Advances in new technology are; delivery of anti-inflammatory hormones thereby reducing arterial wall inflammation by using it in the form of liposomal glucocorticoid carrier [7]. The lipid nanoparticles are used to deliver siRNA antagonistic to the C-C chemokine type 2 pro-inflammatory receptor, and HDL nanoparticles examined 
to deliver simvastatin to inhibit monocyte recruitments [12-14]. In percutaneous coronary interventions, nanotechnology has demonstrated potential benefits by stent coating, gene therapy and stem cells [15-18]. They have been studied for their ability to release drugs as well as promote healing and reduce the rate and extent of restenosis [11]. This selected review aims to examine the role of new technologies in the management of CAD

\section{Utility and Necessity of New Technologies}

Current methods of treatment for heart failure after myocardial infarction are limited to palliation without any cure. Conventional surgical interventions such as coronary artery bypass graft or percutaneous coronary interventions are only able to partially restore myocardial function. There is only a minor improvement in the left ventricular ejection fraction due to reperfusion injury after these interventions [1-3]. The ultimate goal of cardiac repair is to regenerate functionally viable myocardium after myocardial infarction to prevent cardiac death. Identification of the innovative factors is essential in cardiac healing as well as in improving endothelial function of the coronary vasculature via using specialized pro-resolving mediators because the emerging factors provide the key molecular signals for the activation of the reparative cells in both endothelium and myocardium [7,11,1215]. There have been several advancements in the technological care of CAD in the last 3 decades. Of these technologies, stents, gene therapy, stem cells, drug delivery and 3-D printing are most important (Figure 1). Robotic angioplasty and coronary bypass grafting are also emerging to improve the clinical results.

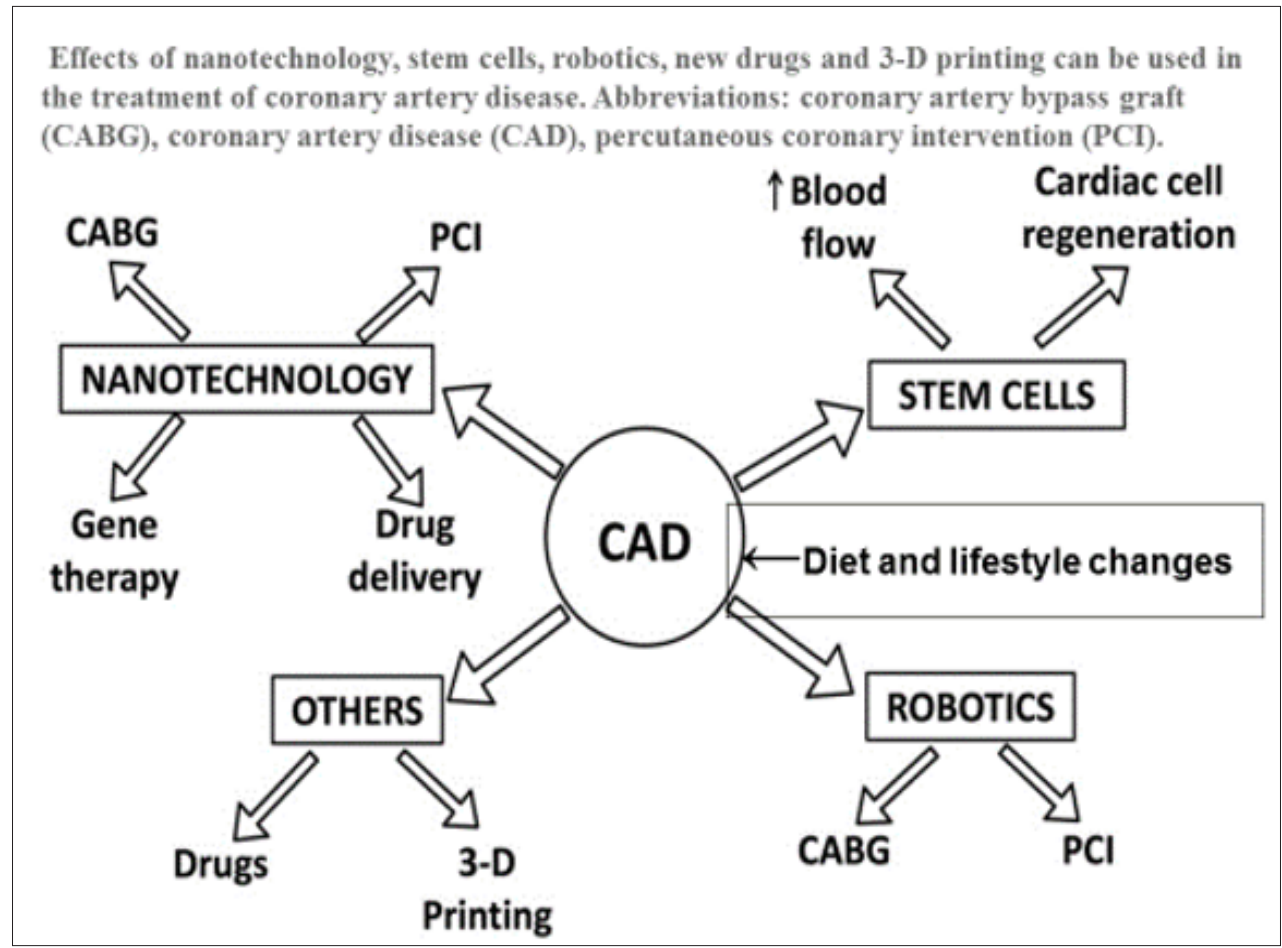

Figure 1: Effects of nanotechnology advancements; stem cells, robotics, new drugs and 3-D printing in the treatment of coronary artery disease. Abbreviations: coronary artery bypass graft (CABG), coronary artery disease (CAD), percutaneous coronary intervention (PCI).(modified from Kandaswami et al. [7].

\section{Stents for Coronary Angioplasty}

Stents are used in coronary thrombosis to allow patency of the vessel in patients with CAD. In an animal model, gelbased nanoparticles combined with anti-proliferative and antiapoptotic agent rapamycin, were studied, which were found to re-endothelialize injured arteries and reduce hyperplasia [15]. Research in drug delivery has shown promise in treating cardiac diseases by using smart nanoparticles such as a pH-dependent delivery of antioxidants [16]. In clinical studies, nano-sized hydroxyapatite coating for controlled release of sirolimus, an immune- suppressive drug coated stent, revealed satisfactory findings [17]. A new gene-eluting metal stent fabricated by bio- inspired surface modification with hyaluronic acid and deposition of DNA/PEI polyplexes has also been developed for clinical use [17]. Similarly, the release of sirolimus was studied using carbon nanoparticle coated stents with consistent drug release, as reported in an in-vitro study [18]. A comparison of the sirolimus-releasing stents with pitavastatin nanoparticle-eluting stents revealed that latter were found to be more efficient in terms of faster endothelial healing while being comparable in other parameters [22].

Endothelial healing and re-endothelialization can restore the injured vessel back to health. Magnetic silica nanoparticles were loaded with rapamycin, coated onto the stent which showed rapid endothelialization in the in-vivo studies [23]. Experimental studies 
reveal that liposome encapsulated alendronate (a bisphosphonate) can reduce restenosis and neo-intimal formations [39]. Polycaprolactone was found to be an effective carrier for nitric oxide to prevent restenosis [24]. Similarly, paclitaxel (antimitotic drug) in the form of albumin-based nanoparticles have shown to have significant anti-proliferative and restenosis effects without significant toxicity even when administered systemically $[11,25,26]$. The nanoparticles in these cases were either used to improve cell membrane permeability (alendronate) or binding capacity to the targeted tissues (paclitaxel) $[1,24,25]$. Polymeric stent coatings in the form of poly (lactic-co-glycolic acid) were proven to have a controlled release of the drug paclitaxel (nanocoatings-64) and polyethylene glycol was proven to reduce platelet adhesion [24]. It has been reviewed that nano-modifications can also help scientists in targeting specific delivery of medications such as collagen IV, chondroitin sulfate, tissue factor, or stents [7].

The promotion of healing by inducing endothelialization of the stent is also possible by nanotechnology in the form of nanofibrous matrix because it can attract endothelial cells, polyhedral oligomericsilsesquioxanepoly-(carbonate-urea) urethane which improve adherence and proliferation of human endothelial cells $[7,11]$. Other healing promoting agents are peptide amphiphilenanofiber coating, for promotion of endothelial cell adhesion and magnetic nanoparticles that cause preferential movement of cells towards the stent [7,11,24-27] (Figure 1). Nanotechnology also has potential applications in finding synthetic alternatives for coronary artery bypass grafts. Researchers have studied the potential of electro-spunnanosized fibrous scaffolds, which may prove to be an alternative synthetic graft for coronary artery bypass graft procedures [7,11]. Another area to choose technology may be targeting drug-eluting stents via gene therapy, because gene eluting stents can be used to overcome restenosis, in-stent thrombosis, and delayed endothelialisation $[28,29]$. In this connection, multiple nano-coatings in the form of hyaluronic acid as a vehicle for pDNA, nanobiohybrid hydrogel, a Tat peptide and DNA, and poly lactic-coglycolic acid nanoparticles as vehicle for PDGF receptor- $\beta$ antisense RNA, have been studied in animal models and have shown promising results [30].

The gene targets have been studied extensively are; antisense oligonucleotide, chitosan-plasmid DNA, Akt1 siRNA, vascular endothelial growth factor, prostacyclin synthase, and endothelial nitric oxide synthase [28]. Recently, magnetic resonance imaging of acute thrombosis has become possible to visualize thrombininhibiting perfluorocarbon nanoparticles that provide a novel strategy for the treatment by using modular, multifunctional micelles $[19,20]$. In an experiment in hyper-cholesterolemic mice, targeted nanoparticles containing the pro-resolving peptide Ac226 has been reported to protect against advanced atherosclerosis [21]. Recently, activation of angiotensin II signaling in different brain sites such as the paraventricular nucleus (PVN), rostral ventrolateral medulla RVLM), and area postrema (AP) has been found to increase the release of norepinephrine, oxidative stress, and inflammation leading to increased cardiac contractility $[8,9]$. It is possible that blocking angiotensin II type 1 receptors decreases sympathetic nerve activity and cardiac sympathetic afferent reflex when therapy is administered to the PVN. The administration of an angiotensin receptor blocker by injection into the AP activates the sympatho-inhibitory baroreflex indicating that receptor blockers act by increasing parasympathetic activity. In chronic HF, in peripheral regions, angiotensin II elevates both norepinephrine release and synthesis and inhibits norepinephrine uptake at nerve endings, which may contribute to the increase in sympathetic nerve activity [8-10]. Of all above technologies, stem cell therapy is most important because it is being used for treatment of both, myocardial dysfunction as well as for CAD.

\section{The Stem Cells}

Of all technologies that are in way for the managements of CAD, stem cells therapy is most interesting along with stenting. It has been suggested to repair myocardial damage and increase blood supply in ischemic conditions of the heart, thereby reversing the effects of CAD [31-38]. In this respect, both vascular growth factors and stem cells have generated a lot of interest as a mode of treatment in patients with CAD [31]. Such therapies aim to improve the blood supply to ischemic areas of the heart by stem cells, as well as promote cardiac cell regeneration (Figure 1). Stem cells provide benefits in one of two ways: by a direct effect of the stem cells, or by paracrine factors secreted by these stem cells [32]. Studies using hematopoietic cells; mononuclear cells and endothelial progenitor cells for various forms of CAD have been contradictory, although some studies have demonstrated a beneficial effect in these patients [33-36]. A new alternative is the creation of induced pluripotent stem cells, for which adult cells are transformed into pluripotent stem cells, similar to embryonic stem cells, but cancer may be an adverse effect $[32,37,38]$.

There is physiological and metabolic evidence that many tissues and cells in the body have intrinsic regenerative potential and undergoes constant turnover throughout adult life [39-42]. It has also been demonstrated that the heart possesses cardiac stem cells that could be responsible for the intrinsic regeneration and turnover throughout adult life [42]. There is physiological cardiac remodeling in response to endurance exercise training in all cardiac cells [43]. These cells are greater in the apices of the atrium and ventricles and are known to be involved in tissue homeostasis [4446]. The reparative potential of these cells is limited, especially in conditions with extensive damage such as myocardial infarction and chronic heart failure [44-48]. There is also an interest to develop and inject multiple stem cells that can communicate with each other, named as a cardio-cluster which are cocktails of cells that include cardiac progenitor cells, mesenchymal stem cells, endothelial progenitor cells and fibroblasts. They have the potential to promote cardiac cell regeneration in disease states where cell function is reduced such as CAD [49].

The stem cells studied in clinical research are ranged from bone marrow to adipose tissue to skeletal muscle stem cells. Bone marrow-derived mononuclear cells are the most readily available cells for transplantation in the body. They are easy to identify based on their cell surface markers and can be isolated 
from the bone marrow [32]. However, their therapeutic potential is low since the harvested cells contain a multitude of cells with a small proportion of stem cells [35,39]. The bone marrow-derived mesenchymal stem cells are found in even lower concentrations than that of mononuclear cells thus requiring several weeks of maturation with different growth factors in the laboratory, prior to therapy. The adipose derived stem cells can be surgically harvested from adipose tissues. They are more abundant in comparison to the bone marrow-derived cells. This drastically reduces the time and cost involved in laboratory procedures to culture them for clinical use [39]. The pluripotent stem cells have a high potential for transformation. Although embryos represent the most obvious source of stem cells, their use has ethical concerns and is in debate.

Additionally, these cells could potentially face rejection when transplanted to a recipient. However, it is possible to reprogram adult cells and transform them into pluripotent cells which have similar properties as embryonic stem cells, thereby being called induced pluripotent stem cells. These cells can be auto-transplanted and therefore would not be rejected but may predispose cancer $[37,41]$. In view of the risk of teratomatous changes, this area requires more research before they can be considered safe for human trials. Another interesting source of stem cell are cardiac stem cells [42-44]. The clinical data for stem cell therapy is in its early days with reported literature covering both non-randomized and randomized trials [50-52]. There is improved left ventricular ejection fraction (LVEF) function following injection of mononuclear stem cells in patients with MI within three months. Improvement in exercise capacity, reduced mortality and scar tissue are shown in a 5-year follow up [50]. Several other studies showed similar effects following treatments with mononuclear stem cells after myocardial infarction [36]. An earlier meta-analysis reported an improvement in LVEF function by $2.99 \%$ following bone marrow stem cell transplantation in patients after MI [51].

However, the meta-analysis did not include recent studies that reported no improvement in left ventricular function [33,34]. In patients suffering from chronic ischemic heart disease, there is reported evidence towards improved cardiac function following the use of bone marrow derived-stem cells [52]. There have been several trials that have studied the clinical efficacy of mesenchymal stem cells. They have reported an improvement in cardiac function and relative safety in the use of mesenchymal stem cells [53-56]. Cardiac derived stem cells have also undergone clinical testing and have shown promising results with an improvement in LVEF [57], an improvement in the left ventricular mass that was viable $[58,94]$, improved quality of life [57], reduced scar mass, improved and safety of the procedure $[57,58]$ due to better regional contractility [59]. In a meta-analysis, a critical evaluation of clinical evidence on the safety and efficacy of autologous adult bone marrow-derived stem/progenitor cells has been examined as a treatment for chronic CAD and congestive heart failure [4]. This meta-analysis included, 38 randomised controlled trials involving 1907 participants; 1114 cell therapy, 793 controls.

Twenty-three trials were at high or unclear risk of selection bias. Treatment with stem cells, was associated with significant decline in the incidence of long-term mortality ( $\geq 12$ months) (risk ratio (RR) 0.42 , 95\% confidence interval (CI) 0.21 to 0.87 ; among 491 participants. Cell therapy was also associated with a long-term reduction in the incidence of non-fatal myocardial infarction (RR 0.38 , 95\% CI 0.15 to 0.97 ; among 345 participants. The incidence of arrhythmias (RR 0.42 , 95\% CI 0.18 to 0.99 ; among 82 participants was also decreased with this treatment. However, there was no evidence that cell therapy has any influence on the risk of rehospitalisation for heart failure (RR 0.63, 95\% CI 0.36 to 1.09; among 375 participants, or composite incidence of mortality, non-fatal myocardial infarction, and/or rehospitalisation for heart failure (RR 0.64, 95\% CI 0.38 to 1.08; among 141 participants = 141 , or long-term left ventricular ejection fraction when measured by magnetic resonance imaging (mean difference $-1.60,95 \% \mathrm{CI}$ -8.70 to 5.50; among 25 participants[4]. The authors suggested that there is low quality evidence indicating that treatment with bone marrow-derived stem/progenitor cells reduces mortality and improves left ventricular ejection fraction over short- and long-term follow-up and may reduce the incidence of non-fatal myocardial infarction and improve chronic CAD and CHF. These findings should be interpreted with caution, as event rates were generally low, leading to a lack of precision.

Interestingly, some patients treated with cardiac stem cells, 10-14 months after myocardial infarction may have similar therapeutic benefit as someone treated earlier, suggesting that cardiac stem cells could be beneficial in chronic ischemia patients [32,50-58]. However, it should be noted that the observed clinical benefit was less than the expected clinical benefit based on prior in vitro and animal studies [32]. Stem cell therapy continues to be a promising treatment modality for CAD. The experimental and clinical studies have shown promising results. However, further research is needed to understand the exact mechanisms of action and the ideal source of stem cells to derive optimum benefit and to further our understanding. Several challenges such as long-term safety and route of administration, have to be overcome. However, the direction of current research looks promising.

\section{3-D Printing}

There are other technologies such as 3-D Printing Cardiac conditions often need 3-D imaging like magnetic resonance imaging, computerized tomography, and 3-D echography to diagnose and treat myocardial damage and athero-thrombosis. Although these images are in 3-D but they are viewed on a 2-D computer screen or films which could be sufficient for some cardiac procedures. However, the current imaging modalities are not effective for more complex interventions. It seems that 3 -D printing has a potential role in CAD because it overcomes these limitations as well as allow for complete visualization, tactile sense, education and surgical planning as well as simulation [60]. It needs additive manufacturing of a model using 3-D data from imaging modalities. It has been observed that 3-D printing could be more effective in planning and treating complex situations (bifurcation lesions) that require stent placement. Radiologists and scientists are trying to see the full potential of 3-D printing, because in cardiology it has tremendous potential in the treatment of congenital defects, cardiac tumors, 
cardiomyopathy, functional flow models, valvular heart diseases, stent placement for CAD and other cardiac surgeries [60-64].

These models can be used in a pulsatile flow loop environment, not only to visualize and understand complex flow patterns but also to simulate interventions [63]. It is possible to visualize 3-D printed heart with coronary arteries by this technology, for examination of the extent of occlusion and stenosis in CAD. Compared to imaging and treatment modalities, 3-D printed models are also useful in CAD research [63]. Models of tissue engineering are examined to fabricate stem cells along with extracellular matrix (tissue printing) for implantation in the body. In vitro studies have been successful in tissue printing cardiac cells in different scaffolds. The implantation of printed tissue in epicardial tissues showed beneficial effects including decline in adverse remodeling and improved perfusion in the models of myocardial infarction.

In brief, it seems that nanotechnology has led to an interesting and promising direction in the treatment of CAD and CHF. It has valuable potential in delivering drugs that are otherwise limited by their pharmacokinetics. Its applications in stent and gene therapy are potentially useful for future therapeutics based on these modalities. Randomized controlled trials are needed to establish potential evidence to support the use of these newer technologies for therapy of CAD. This needs to be carried out with potential collaboration between researchers, engineers, biomedical engineers, nanotechnologist and physicians. and clinicians.

\section{References}

1. Benjamin EJ, Virani SS, Callaway CW, Chamberlain AM, Chang AR, et al. (2018) Heart Disease and Stroke Statistics-2018 Update: A Report from the American Heart Association. Circulation 137(12): e67-e492.

2. (2015) GBD 2013 Mortality and Causes of Death Collaborators, Global, regional, and national age-sex specific all-cause and cause-specific mortality for 240 causes of death, 1990-2013: a systematic analysis for the Global Burden of Disease Study 2013. Lancet 385(9963): 117-171.

3. Sacco RL, Roth GA, Reddy KS, Arnett DK, Bonita R, et al. (2016) The heart of 25 by 25: achieving the goal of reducing global and regional premature deaths from cardiovascular diseases and stroke: a modeling study from the American Heart Association and World Heart Federation. Circulation 133(23): e674-e690.

4. Khan K, Gasbarrino K, Mahmoud I, Makhoul G, Yu B, et al. (2018) Bioactive scaffolds in stem-cell-based therapies for cardiac repair: protocol for a meta-analysis of randomized controlled preclinical trials in animal myocardial infarction models. Syst Rev 7(1): 225.

5. Leoni G, Soehnlein O (2018) (Re) Solving repair after myocardial infarction. Front Pharmacol 9: 1342.

6. Fisher SA, Doree C, Mathur A, Taggart DP, Martin Rendon E (2016) Cochrane Database Syst Rev 12: CD007888.

7. Kandaswamy E, Zuo Li (2018) Recent advances in treatment of coronary artery disease: role of Science and Technology. Int J Mol Sci 19(2): 424.

8. Singh RB, Hristova K, Fedacko J, Elkilany G, Cornelissen G (2018) Chronic heart failure: a disease of the brain. Heart Fail Rev.

9. Singh RB, Fedacko J, Sharma JP, Vargova V, Sharma R, et al. (2010) Association of inflammation, heavy meals, magnesium, nitrite, and coenzyme Q10 deficiency and circadian rhythms with risk of acute coronary syndromes. World Heart J 4(3): 219-228.

10. Dhalla AK, Hill M, Singal PK (1996) Role of oxidative stress in the transition of hypertrophy to heart failure. J Am Coll Cardiol 28(2): 506514.
11. Rhee JW, Wu JC (2013) Advances in nanotechnology for the management of coronary artery disease. Trends Cardiovasc Med 23(2): 39-45.

12. Leuschner F, Dutta P, Gorbatov R, Novobrantseva TI, Donahoe JS, et al. (2011) Therapeutic siRNA silencing in inflammatory monocytes in mice. Nat Biotechnol 29: 1005-1010.

13. Lobatto ME, Fayad ZA, Silvera S, Vucic E, Calcagno C, et al. (2010) Multimodal clinical imaging to longitudinally assess a nanomedical antiinflammatory treatment in experimental atherosclerosis. Mol Pharm 7(6): 2020-2029.

14. Tang J, Lobatto ME, Hassing L, Van Der Staay S, Van Rijs SM, et al. (2015) Inhibiting macrophage proliferation suppresses atherosclerotic plaque inflammation. Sci Adv 1(3).

15. Reddy MK, Vasir JK, Sahoo SK, Jain TK, Yallapu MM, et al. (2008) Inhibition of apoptosis through localized delivery of rapamycin-loaded nanoparticles prevented neointimal hyperplasia and reendothelialized injured artery. Circ Cardiovasc Interv 1(3): 209-216.

16. Tang C, Amin D, Messersmith PB, Anthony JE, Prudhomme RK, et al. (2015) Polymer directed self-assembly of pH-responsive antioxidant nanoparticles. Langmuir 31(12): 3612-3620.

17. Costa JR, Abizaid A, Costa R, Feres F, Tanajura LF, et al. (2009) 1-year results of the hydroxyapatite polymer-free sirolimus-eluting stent for the treatment of single de novo coronary lesions: The VESTASYNC I trial. JACC Cardiovasc Interv 2(5): 422-427.

18. Kim TG, Lee Y, Park TG (2010) Controlled gene-eluting metal stent fabricated by bio-inspired surface modification with hyaluronic acid and deposition of DNA/PEI polyplexes. Int J Pharm 384(1-2): 181-188.

19. Rajender G, Narayanan NG (2010) Liquid chromatography-tandem mass spectrometry method for determination of Sirolimus coated drug eluting nano porous carbon stents. Biomed Chromatogr 24(3): 329-334.

20. Myerson J, He L, Lanza G, Tollefsen D, Wickline S (2011) Thrombininhibiting perfluorocarbon nanoparticles provide a novel strategy for the treatment and magnetic resonance imaging of acute thrombosis. J Thromb Haemost 9(7): 1292-1300.

21. Peters D, Kastantin M, Kotamraju VR, Karmali PP, Gujraty K, et al. (2009) Targeting atherosclerosis by using modular, multifunctional micelles. Proc Natl Acad Sci USA 106(24): 9815-9819.

22. Fredman G, Kamaly N, Spolitu S, Milton J, Ghorpade D, et al. (2015) Targeted nanoparticles containing the proresolving peptide Ac2-26 protect against advanced atherosclerosis in hypercholesterolemic mice. Sci Transl Med 7(275): 27520.

23. Tsukie N, Nakano K, Matoba T, Masuda S, Iwata E, et al. (2013) Pitavastatin-incorporated nanoparticle-eluting stents attenuate instent stenosis without delayed endothelial healing effects in a porcine coronary artery model. J Atheroscler Thromb 20(1): 32-45.

24. Lu J, Liong M, Li Z, Zink JI, Tamanoi F (2010) Biocompatibility, biodistribution, and drug-delivery efficiency of mesoporous silica nanoparticles for cancer therapy in animals. Small 6(16): 1794-1805.

25. Acharya G, Lee CH, Lee Y (2012) Optimization of cardiovascular stent against restenosis: Factorial design-based statistical analysis of polymer coating conditions. PLoS ONE 7: e43100.

26. Chan JM, Rhee JW, Drum CL, Bronson RT, Golomb G, et al. (2011) In vivo prevention of arterial restenosis with paclitaxel-encapsulated targeted lipid-polymeric nanoparticles. Proc Natl Acad Sci USA 108(48): 1934719352.

27. Chorny M, Fishbein I, Yellen BB, Alferiev IS, Bakay M, et al. (2010) Targeting stents with local delivery of paclitaxel-loaded magnetic nanoparticles using uniform fields. Proc Natl Acad Sci USA 107(18): 8346-8351.

28. Bakhshi R, Darbyshire A, Evans JE, You Z, Lu J, et al. (2011) Polymeric coating of surface modified nitinol stent with POSS-nanocomposite polymer. Colloids Surf B Biointerfaces 86(1): 93-105. 
29. Yin RX, Yang DZ, Wu JZ (2014) Nanoparticle drug- and gene-eluting stents for the prevention and treatment of coronary restenosis. Theranostics 4(2): 175-200.

30. Sun D, Zheng Y, Yin T, Tang C, Yu Q et al. (2014) Coronary drug-eluting stents: From design optimization to newer strategies. J Biomed Mater Res A 102(5): 1625-1640.

31. Paul A, Shao W, Shum Tim D, Prakash S (2012) The attenuation of restenosis following arterial gene transfer using carbon nanotube coated stent incorporating TAT/DNA(Ang1+Vegf) nanoparticles. Biomaterials 33(30): 7655-7664.

32. Kastrup J (2010) Gene therapy and angiogenesis in patients with coronary artery disease. Expert Rev Cardiovasc Ther 8(8): 1127-1138.

33. Kastrup J (2011) Stem cells therapy for cardiovascular repair in ischemic heart disease: How to predict and secure optimal outcome? EPMA J 2(1): 107-117.

34. Janssens S, Dubois C, Bogaert J, Theunissen K, Deroose C, et al. (2006) Autologous bone marrow-derived stem-cell transfer in patients with ST-segment elevation myocardial infarction: Double-blind, randomised controlled trial. Lancet 367(9505): 113-121.

35. Lunde K, Solheim S, Aakhus S, Arnesen H, et al. (2006) Intracoronary injection of mononuclear bone marrow cells in acute myocardial infarction. N Engl J Med 355: 1199-1209.

36. Perin EC, Dohmann HF, Borojevic R, Silva SA, Sousa AL, et al. (2003) Transendocardial, autologous bone marrow cell transplantation for severe, chronic ischemic heart failure. Circulation 107(18): 2294-2302.

37. Schächinger V, Erbs S, Elsässer A, Haberbosch W, Hambrecht R, et al. (2006) Intracoronary bone marrow-derived progenitor cells in acute myocardial infarction. N Engl J Med 355: 1210-1221.

38. Gunaseeli I, Doss MX, Antzelevitch C, Hescheler J, Sachinidis A (2010) Induced pluripotent stem cells as a model for accelerated patient- and disease-specific drug discovery. Curr Med Chem 17(8): 759-766.

39. Takahashi K Yamanaka S (2006) Induction of pluripotent stem cells from mouse embryonic and adult fibroblast cultures by defined factors. Cell 126(4): 663-676.

40. Piuzzi NS, Chahla J, Jiandong H, Chughtai M, LaPrade RF, et al. (2017) Analysis of cell therapies used in clinical trials for the treatment of osteonecrosis of the femoral head: A systematic review of the literature J Arthroplast 32(8): 2612-2618.

41. Lin K, Matsubara Y, Masuda Y, Togashi K, Ohno T, et al. (2008) Characterization of adipose tissue-derived cells isolated with the Celution system Cytotherapy 10(4): 417-426.

42. Li, JY Christophersen, NS Hall, V Soulet, D Brundin (2008) P Critical issues of clinical human embryonic stem cell therapy for brain repair. Trends Neurosci 31(3): 146-153.

43. Beltrami AP, Barlucchi L, Torella D, Baker M, Limana F, et al. (2003) Adult cardiac stem cells are multipotent and support myocardial regeneration Cell 114(6): 763-776.

44. Ellison GM, Waring CD, Vicinanza C, Torella D (2012) Physiological cardiac remodelling in response to endurance exercise training: Cellular and molecular mechanisms Heart 98(1): 5-10.

45. Chan SSK, Shueh YZ, Liu YW, Hsieh PCH (2009) Harnessing endogenous intra- and extra-cardiac stem cells for cardiac regeneration-Hope or hype? Drug Discov Today Ther Strateg 6: 127-133.

46. Barile L, Messina E, Giacomello A, Marbán E (2007) Endogenous cardiac stem cells. Prog Cardiovasc Dis 50(1): 31-48.

47. Leri (2009) A Human cardiac stem cells: The heart of a truth. Circulation 120: 2515-2518.

48. Hatzistergos KE, Quevedo H, Oskouei BN, Hu Q Feigenbaum GS, et al. (2010) Bone marrow mesenchymal stem cells stimulate cardiac stem cell proliferation and differentiation Circ Res 107(7): 913-922.
49. Ferreira-Martins J, Ogórek B, Cappetta D, Matsuda A, Signore S, et al. (2012) Cardiomyogenesis in the developing heart is regulated by c-kitpositive cardiac stem cells. Circ Res 110(5): 701-715.

50. Nguyen N1, Sussman MA (2015) Rejuvenating the senescent heart Curr Opin Cardiol 2015 30(3): 235-239.

51. Yousef M, Schannwell CM, Köstering M, Zeus T, Brehm M, et al. (2009) The BALANCE Study: Clinical benefit and long-term outcome after intracoronary autologous bone marrow cell transplantation in patients with acute myocardial infarction. J Am Coll Cardiol 53(24): 2262-2269.

52. Martin-Rendon E, Brunskill SJ, Hyde CJ, Stanworth SJ, Mathur A, et al. (2008) Autologous bone marrow stem cells to treat acute myocardial infarction: A systematic review. Eur Heart J 29(15): 1807-1818.

53. Veltman CE, Soliman OI, Geleijnse ML, Vletter WB, Smits PC, et al. (2008) Four-year follow-up of treatment with intramyocardial skeletal myoblasts injection in patients with ischaemic cardiomyopathy. Eur Heart J 29(11): 1386-1396.

54. Hare JM, Fishman JE, Gerstenblith G, DiFede Velazquez DL, Zambrano JP, et al. (2012) Comparison of allogeneic vs autologous bone marrowderived mesenchymal stem cells delivered by transendocardial injection in patients with ischemic cardiomyopathy: The POSEIDON randomized trial. JAMA 308(22): 2369-2379.

55. Hare JM, Traverse JH, Henry TD, Dib N, Strumpf RK, et al. (2009) A randomized, double-blind, placebo-controlled, dose-escalation study of intravenous adult human mesenchymal stem cells (prochymal) after acute myocardial infarction. J Am Coll Cardiol 54(24): 2277-2286.

56. Lee JW, Lee SH, Youn YJ, Ahn MS, Kim JY, et al. (2014) A randomized, openlabel, multicenter trial for the safety and efficacy of adult mesenchymal stem cells after acute myocardial infarction. J Korean Med Sci 29(1): 2331.

57. Mushtaq M, DiFede DL, Golpanian S, Khan A, Gomes SA, et al. (2017) Rationale and design of the Percutaneous Stem Cell Injection Delivery Effects on Neomyogenesis in Dilated Cardiomyopathy (the POSEIDONDCM study): A phase I/II, randomized pilot study of the comparative safety and efficacy of transendocardial injection of autologous mesenchymal stem cell vs allogeneic mesenchymal stem cells in patients with non-ischemic dilated cardiomyopathy. J Cardiovasc Transl Res 7 (9): 769-780.

58. Bolli R, Chugh AR, D’Amario D, Loughran JH, Stoddard MF, et al. (2011) Cardiac stem cells in patients with ischaemic cardiomyopathy (SCIPIO): Initial results of a randomised phase 1 trial. Lancet 378(9806): 18471857.

59. Chugh AR, Beache GM, Loughran JH, Mewton N, Elmore JB, et al. (2012) Administration of cardiac stem cells in patients with ischemic cardiomyopathy: The SCIPIO trial: Surgical aspects and interim analysis of myocardial function and viability by magnetic resonance Circulation 126(11 supp 1): S54-S64.

60. Makkar RR, Smith RR1, Cheng K1, Malliaras K1, Thomson LE, et al. (2012) Intracoronary cardiosphere-derived cells for heart regeneration after myocardial infarction (CADUCEUS): A prospective, randomised phase 1 trial. Lancet 379(9819): 895-890.

61. Schmauss D, Haeberle S, Hagl C, Sodian R (2015) Three-dimensional printing in cardiac surgery and interventional cardiology: A singlecentre experience. Eur J Cardiothorac Surg 47(6): 1044-1052.

62. Bartel T, Rivard A, Jimenez A, Mestres CA, Muller S (2017) Medical threedimensional printing opens up new opportunities in cardiology and cardiac surgery. Eur Heart J 39(15): 1246-1254.

63. Valverde I (2017) Three-dimensional printed cardiac models: Applications in the field of medical education, cardiovascular surgery and structural heart interventions. Rev Esp Cardiol 70(4): 282-291.

64. Vukicevic M, Mosadegh B, Min JK, Little SH (2017) Cardiac 3D printing and its future directions JACC Cardiovasc Imaging 10(2): 171-184. 
ISSN: 2574-1241

DOI: 10.26717/BJSTR.2019.13.002411

Viliam Mojto. Biomed J Sci \& Tech Res

(c) This work is licensed under Creative

Submission Link: https://biomedres.us/submit-manuscript.php

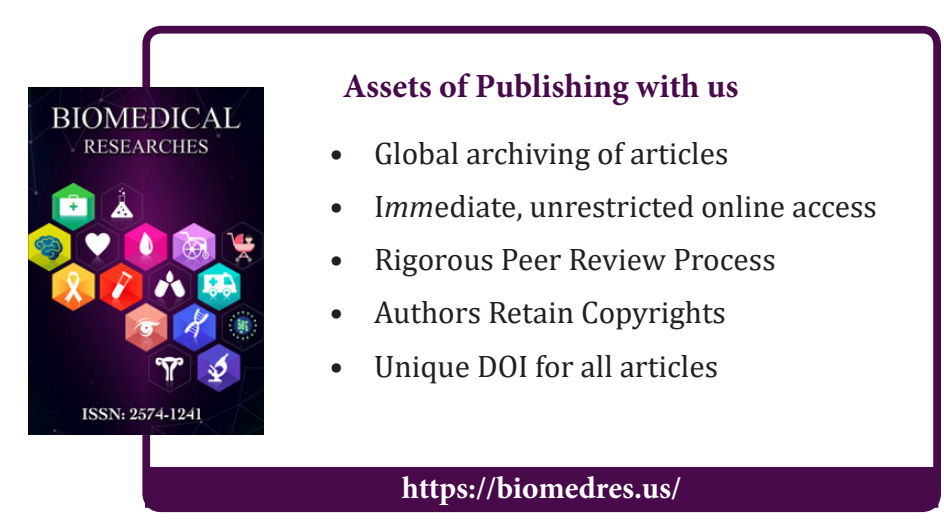

